\title{
Paraquat poisoning: evidence of systemic toxicity after dermal exposure
}

\author{
K. TUNGSANGA \\ M.D. \\ S. ISRASENA \\ M.D. \\ S. CHUSILP \\ M.D., Ph.D. \\ V. SITPRIJA \\ M.D., Ph.D., F.A.C.P. \\ Department of Medicine, Chulalongkorn Hospital Medical School, Bangkok, Thailand
}

\begin{abstract}
Summary
Exposure of the scrotal skin to a concentrated paraquat solution led to renal and respiratory failure and to hepatic damage with eventual recovery of the patient. Dermal exposure to paraquat, especially to the scrotum may produce serious systemic toxicity.
\end{abstract}

KEY WORDS: paraquat, poisoning, dermal exposure.

\section{Introduction}

The clinical toxicity of paraquat $\left(1,1^{\prime}\right.$ dimethyl, $4,4^{\prime}$ bipyridylium dichloride) has been well documented. Ingestion of paraquat, the common route of poisoning, causes damage mainly to kidney, lung and liver. Toxicity from paraquat spray is often mild and local. Death has been reported following subcutaneous injection of paraquat (Almog and Tal, 1967). A fatal case of respiratory failure resulting from exposure of abraded skin to paraquat has been described (Newhouse, McEvoy and Rosenthal, 1978). A fatal case has followed application of a $20 \%$ paraquat solution to the beard and scalp (Binns, 1976). Systemic toxicity after contamination of intact skin to improperly diluted paraquat preparation has also been observed (Levin, Klaff and Ferguson, 1979). We describe here a non-fatal case of renal and pulmonary failure after paraquat exposure to intact skin.

\section{Case report}

A Thai male farmer, 44 years of age, mistakenly used the liquid (Gramoxone $\AA$, containing $20 \%$ paraquat dichloride) in one of the toilet containers to clean his perineum. This gave a burning sensation and he immediately washed his perineum with soap and water. A few days later, an ulcer developed in this area and he was admitted to a local health centre. Three weeks after admission, the physician noticed a rise in serum urea nitrogen and creatinine. The patient was transferred to Chulalongkorn Hospitaใ Medical School 26 days after the incident. Physicalu findings were unremarkable apart from a localizedo erythematous, oozing, macerated denuded area of scrotal sac with a purulent discharge. Full bloodcount and urinalysis were normal. Blood urea was $75.0 \mathrm{mmol} / \mathrm{litre}$; creatinine, $1025 \mu \mathrm{mol} / \mathrm{litre}$; aspar tate aminotransferase (SGOT), $1.28 \mu \mathrm{mol} / \mathrm{sec} /$ litre $\overrightarrow{\mathrm{O}}$ total bilirubin, $10.3 \mu \mathrm{mol} /$ litre; the direct bilirubofn $1.71 \mu \mathrm{mol} / \mathrm{litre}$; alkaline phosphatase, $1.92 \mu \mathrm{m}$ H/ $\mathrm{sec} /$ litre; sodium, $133 \mathrm{mmol} / \mathrm{litre}$; potassium, $\mathrm{mmol} /$ litre; chloride, $95 \mathrm{mmol} /$ litre and bicarbonate $18.1 \mathrm{mmol} /$ litre. Arterial blood gas analysis showeक arterial pH 7.43; $\mathrm{PaO}_{2} 72 \mathrm{mmHg}$ and $\mathrm{PaCO}_{2} 37$ mmHg. X-ray film of the chest revealed diffuse interstitial and alveolar infiltration. Paraquat was no흘 detected in serum and urine.

The daily urine output ranged from 0.5 to 2.0 litres being compatible with acute non-oliguric renal fail ure. Peritoneal dialysis was started on the 3rd day of hospitalization. Cloxacillin and gentamicin were prescribed on the 9th day for a staphylococca 3 peritonitis with a satisfactory response. Ten days after admission, (and 36 days after the exposure to paraquat), he developed acute respiratory distress with a $\mathrm{PaO}_{2}$ of $30 \mathrm{mmHg}$, requiring mechanica ventilation for 5 days. Ventilation was discontinue 8 on the 15th day after admission.

Liver biopsy performed on the 33rd day aftef paraquat exposure showed mild swelling of hepato cytes with mild focal cell necrosis. Neither fatt metamorphosis nor cholestasis was seen. Kidneyw biopsy was obtained on the 48th day after exposure to paraquat and showed mild tubular necrosiso diffuse interstitial fibrosis and inflammatory celp infiltration. The immunofluorescent study was nega tive.

Renal function gradually recovered and he lef hospital 53 days after the paraquat exposure. 


\section{Discussion}

We present here a patient who developed a skin lesion and hepatic, renal and pulmonary injury following paraquat exposure to the perineum. The systemic toxicity was perhaps mild and unrecognised until 3 weeks later when blood chemistry was obtained. Although sepsis can mediate acute renal and respiratory failure, there was no fever or other clinical evidence of toxaemia. The failure to detect paraquat in blood and urine was not surprising so long after exposure.

In occupational exposure, systemic toxicity of paraquat is rare, but local damage to the skin and skin appendages is not uncommon. Burning, urticaria, ulceration, nail damage, epistaxis and corneal lesion are among the local effects of paraquat contamination (Swan, 1969). However, dermal contact with a concentrated preparation is not free from systemic effects. Jaros (1978) reported a fatal case of skin exposure to paraquat and Levin et al. (1979) demonstrated considerable pulmonary changes in rats following repeated challenges with paraquat solution to normal skin similar to those observed after oral ingestion.

In our case, absorption through the rectal mucosa was unlikely since the skin of the perianal area and the rectal mucosa were well preserved. Absorption was through the intact skin of the perineum. In spite of the short exposure time, a concentrated preparation of paraquat was used, and the soft and highly vascular scrotal skin might allow significant absorption to produce systemic effects. This report adds to the literature on the potential hazards of exposure of normal skin to paraquat. Systemic effects are not common, but may occur especially when a concentrated solution contacts scrotal skin. Hence, protective measures to prevent dermal contamination by paraquat must be strictly observed.

\section{References}

ALMoG, C.H. \& TAL, E. (1967) Death from paraquat after subcutaneous injection. British Medical Journal, 3, 721.

BINNS, C.W. (1976) The use and abuse of drugs in tropical Africa. Papua New Guinea Medical Journal, 19, 105.

JAROS, F. (1978) Acute percutaneous paraquat poisoning. Lancet, i, 275.

LeVin, P.J., KlafF, L.J., Rose, A.F. \& Ferguson, A.D. (1979) Pulmonary effects of contact exposure to paraquat: A clinical and experimental study. Thorax, 34, 150.

Newhouse, M., MCEvoy, D. \& Rosenthal, D. (1978) Percutaneous paraquat absorption. Archives of Dermatology, 114, 156.

SWAN, A.A.B. (1969) Exposure of spray operators to paraquat. British Journal of Industrial Medicine, 26, 322.

(Accepted 18 August 1982) 